\title{
Sertkaya, O. F. - Uzuntaş, H. Dede Korkut'un Günbed Yazması Üzerine Araştırmalar ve İncelemeler, Bilge Kültür-Sanat Yayınları, İstanbul, 2020, 176 sayfa, ISBN: 978-605-7931-98-6
}

\section{Hülya UZUNTAŞ*}

Türk dili ve folklorunun ortak mahsulü olan Dede Korkut Kitabı'nın ilim âlemince bilinen ilk yazması bir giriş ve on iki hikâyeyi ihtiva eden Dresden yazması, ikincisi ise bir giriş ile Dresden yazmasındaki altı hikâyeyi ihtiva eden Vatikan yazmasıdır. 2018 yılının Aralık ayında Tahran/İan'da Veli Muhammed Hoca isimli kitapsever bir Türkmen tarafindan 61 sahifelik Arap harfli yeni bir Dede Korkut yazması satın alınmıştır. Gün yüzüne çıktığı andan itibaren Türkoloji ilim âleminde farklı isimlerle ${ }^{1}$ anılan bu yazma için kullanılan isimlerden biri de Günbed yazmasıdır.

Muhtelif araştırmacılar tarafından yayımlanan Günbed yazmasının ${ }^{2}$ konu edildiği on araştırma ve inceleme yazısından müteşekkil Dede Korkut'un Günbed Yazması Üzerine Araştırmalar ve Incelemeler başlıklı 176 sahifelik bir çalışma Temmuz 2020'de Bilge Kültür-Sanat Yayınları arasından çıkmıştır.

9 müstakil (Sertkaya $8[1,2,3,5,6,7,8,10$. yazılar] \& Uzuntaş 1 [9. yazı]) ve 1 müşterek (Sertkaya ve Uzuntaş [4. yazı]) toplam 10 yazıyı ihtiva eden eserin ön kapak sahifesinde, yazmada müstensih tarafindan kırmızı mürekkeple Dede Korkut ağzından yazılan iki açıklama (bu soyda Dedenüñ müdde'āsl budur ki her kim belki her neste öz haddinde ve kemālinde olsa yahşl-dur ehl-i isti 'dādl kemāl tahṣiline tergìib èdüb mev'ize èyler [2/6]; Dedenüñ bu soyda mațlabı budur ki her mümkin muhtācdur öz żātında pes insān ki ekmel-i mümkinātdur muhtācrak-dur pes her kim dünyā ve āhiret refāhıçün her neye muḥtācdurur hikmet-i bālig̀a muhtā̄-dan ileri

\footnotetext{
*Dr., Trakya Üniversitesi, Türk Dili ve Edebiyatı Bölümü, hulyauzuntas@trakya.edu.tr, ORCID: 0000-0003-2306-5483

${ }^{1}$ Yazmanın isimlendirilmesi için bk. Sertkaya ve Uzuntaş, 2020: 9-10.

${ }^{2}$ Günbed yazması neşirleri için bk. Sertkaya ve Uzuntaş, 2020: 10.
}

Geliş Tarihi / Received: 21.11.2020

Kabul Tarihi / Accepted: 19.01.2021

Yayın Tarihi / Published: 29.01.2021 
muhtāc'unileyhi halk édübdür [4/6-8]) orijinal imlâlarıyla, el yazması metnin her sahifesinde kullanılan çerçeve içerisinde verilerek eserin inceleme konusu ile bir bütünlük oluşturulmuştur. İç kapak sahifesinden (s. 3) sonra, 04.12.2020 tarihinde 70 yaşına girecek olan Azerbaycanlı bilim adamı Kamal Mehdioğlu Abdulla'ya ithaf edilen eserin ithaf sahifesi (s. 5) ve içindekiler listesi (s. 7) yer alır. Ardından Veli Muhammed Hoca'nın yazmayı satın alması ve ilim âleminin yazmadan haberdar olma süreci, yazmanın isimlendirilmesi, yazma neşirlerinin künyesi ve eser içerisindeki 10 yazı hakkında bilgi verilen Sunuş (s. 9-11) yazısı gelir. Sunuştan sonra eserin ana bölümünü oluşturan 10 yazı yer alır.

\section{Dede Korkut'un Üçüncü Elyazması (Soylamalar ve İki Yeni Boy ile Türkmen Sahra Nüshası) (s. 13-15)}

Osman Fikri Sertkaya'nın bu yazısı, yazmanın bilim âlemince tanınmasından başlayıp Günbed yazması nâşirlerinden Yusuf Azmun'a ait çalışmanın kendisi ve Timur Kocaoğlu tarafindan okunması, yazmanın kopyasının Azmun'a intikali, Azmun'un yazmaya verdiği isim, yazmanın muhtevası ile Azmun ve neşri hakkında bilgi verilen duyuru metnidir. Dijital ortamdaki bir sosyal paylaşım sitesinden 11 Haziran 2019 tarihinde paylaşılan bu yazı el yazması metin ve Azmun neşri hakkında ilk bilgileri ihtiva eden yazılardan biri olması bakımından mühimdir.

2. Yusuf AZMUN, Dede Korkut'un Üçüncü Elyazması, Yeni Soylamalar ve Boylar (Hikâyeler) ile Türkmen Sahra Nüshası, Giriş Metin - Çeviri - Sözlük - Tipkıbasım, Kutlu Yayınevi, İstanbul, 11.06.2019, 176 s. (s. 17-24)

Günbed yazması nâşirlerinden Yusuf Azmun'un Haziran 2019'da Kutlu Yayınevi tarafindan basılan Dede Korkut'un Üçüncü Elyazması, Yeni Soylamalar ve Boylar (Hikâyeler) ile Türkmen Sahra Nüshası, Giriş - Metin - Çeviri - Sözlük - Tipkıbasım isimli çalışmasının Osman Fikri Sertkaya tarafindan hazırlanan tanıtma yazısıdır. Yusuf Azmun'un el yazması metni temini, yazmanın ilim âlemine duyurulması, Osman Fikri Sertkaya ve Timur Kocaoğlu tarafindan Yusuf Azmun'un hazırladığı metnin okunması ile ilgili bilgi verildikten sonra el yazmasındaki 27 soylamadan Salur Kazan'nn Dresden ve Vatikan yazmalarında zikredilmeyen Deli Dönmez şeklindeki adının geçtiği serbest hece vezniyle yazılan altı bentlik 17. soylamanın metni (38/1-39/13) (s. 18-19), ardından da Şecere-i Terâkime'deki yedi dörtlük şeklinde 12'li hece vezni ile yazılan Salur Kazan ile ilgili soylamanın metni (s. 20) verilmiştir. Yazma hakkında kısa bir girişten sonra Azmun neşrinin tanıtımına başlanmış, el yazmasında Sertkaya tarafından tespit edilen dil 
özellikleri listelenmiş, ardından neşrin tanıtımına devam edilmiştir. Son olarak yazmada zikredilen şahıs isimlerinden bazıları verilmiş, kullanılan Moğolca kelimelerden 14 tanesi (cerasın, cıda, cüldü, dalda, daruga, gaburka, hündür, kalhan, keçige, nöker, sadak, şilalga, tavulga, tumçuk) alfabetik olarak listelendikten sonra 17. soylamanın tıpkıbasımı verilerek (s. 23-24) tanıtma tamamlanmıştır.

3. Dede Korkut'un Günbed Yazmasının Azmun ile Ekici Yayımlarında Düzeltmeler ve Tamamlamalar (s. 25-46)

Osman Fikri Sertkaya bu yazısı ile "Azmun ve Ekici neşirlerindeki yanlış okumaların, kendisine göre, doğrularını vererek ve yanlış okuma ile anlamlandırmaların sebeplerini açıklayarak okuyucunun metni doğru anlamaya çalışması ve kendi kitabından bunları düzeltmesini" (Sertkaya, 2020: 31) amaçlamıştır.

Haziran 2019'da Türkiye'de üç farklı neşri yapılan Günbed yazmasının Veli Muhammed Hoca tarafindan satın alınmas1, farklı zamanlarda muhtelif araştırmacılara kopyasının gönderilmesi, yazmanın bilim âlemine duyurulması ile ilgili hususlar "yazmanın hikâyesi” alt başlığında (s. 25-27) ele alınmıştır. Ardından "soylamalar" alt başlığında Azmun ve Ekici neşirlerindeki soylama tespitlerinin farklılığ1, "kelimelerde kalınlık-incelik uyumu" alt başlığında her iki nâşirin kalın veya ince sıralı okuduğu bazı kelimelerin (Azmun: söyledi, Ekici: soyladl; Azmun: urulmak, Ekici: örülmak vd.) listesinin karşılaştırmalı tablosu, "Azmun ile Ekici okumalarının karşılaş̧tırılması" alt başlığında ise iki nâşirin birbirinden farklı okudukları kelimelerden 25 tanesinin (Azmun: iyesi, Ekici: ayast; Azmun: Eres, Ekici: Aras vd.) listesi verilmiştir.

Azmun ve Ekici neşirlerindeki yaklaşık 50 kelimenin farklı okunuşları değerlendirilirken ilgili kelime veya ibârelerin doğru okunuşları ve bu okunuşlara göre nasıl anlamlandırılmaları gerektiği, zaman zaman başka metinler ve çalışmalardan da örnekler verilerek (Azmun: kôl, Ekici: göl. krş. Şehriyâr 'Haydar Baba'ya Selâm': Kôl dibinnen dovşan galhup gaçanda [Muharrem Ergin, Azeri Türkçesi, 1971, s. 102] vb.) (Sertkaya, 2020: 33), gerekçeleri ile birlikte Sertkaya tarafindan izah edilmiştir. Çalışmada faydalanılan kaynaklar bibliyografya (s. 45-46) kısmında verilmiştir. 


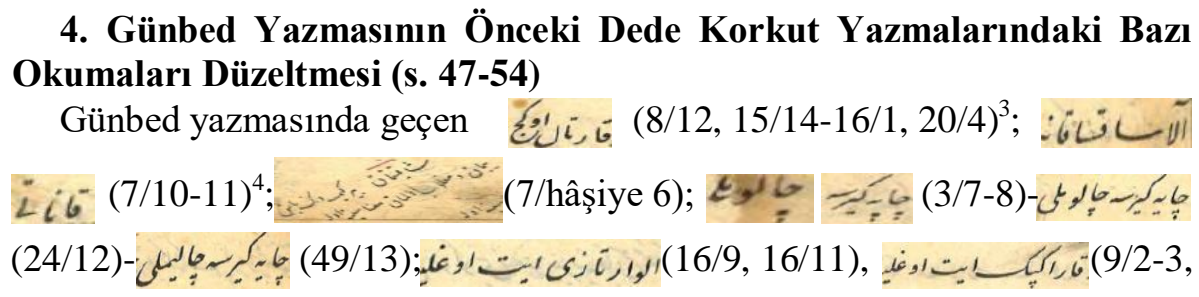

16/2, 20/7) paralel şekillerden hareketle Dresden ve varsa Vatikan yazmalarındaki ilgili kelime ve ibârelerin okunuş ve anlamlarına açılık getirilmiştir.

\section{Dede Korkut'un Günbed Yazmasında Geçen 50 Moğolca Kelime} (s. 55-81)

Bu yazıda "Günbed yazmasında geçen 49 kelime ile bir yer adı olmak üzere 50 kelime" (Sertkaya, 2020: 56) incelenmiştir. Yer adı en sonda olacak şekilde alfabetik olarak listelenen kelimeler (aka [=aga], bahadır, balçak, bürgüt, cangं bègi, car, carasin, cebedār, çerge, cibir, cıda, cılav, cüldü, çak[=çag்], dalda, dal, darug்a, ġabırka, gecige, ibçin < ipçin, kākül, kalhan, karanku [=karangu], karçıgay, karl karu, ker, kulun/kula:n/kolan, kurban, nöker, oba, onba, osal, öle+, ölke, öndür, ötelgi, sadak, sìbe, şilalga, şilen > şölen, siñkur şıñkur soñkur suñkur şuñkur; şuñkar, tasma,

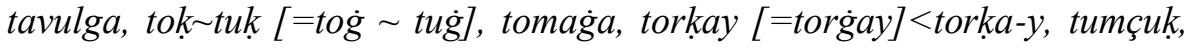
Kaplantu) açıklanarak yazmada kullanıldıkları ibâre veya cümleler sıralanmıştır. Çalışmanın sonunda incelenen elli kelimenin yer aldığ 1 tablo (s. 78), ardından kronolojik olarak listelenen kısaltmalı bibliyografya (s. 7980) ve isim-soy isim şeklinde alfabetik olarak listelenen bibliyografya (s. 81) verilmiştir.

6. Prof. Dr. Ramiz Asker'in Dede Korkut Yayını Üzerine (s. 83-86)

Azerbaycanlı Türkologlardan Prof. Dr. Ramiz Asker'in 2019 y1lında Bakü'de 978-9952-37-299-1 ISBN numarası ile yayımlanan 160 sahifelik “Kitabi-Dədə Qorqud"un Üçüncü Olyazması adlı çalışmasının 19.10.2019 tarihinde dijital platformdaki bir sosyal paylaşım sitesinden paylaşılan duyuru metnidir. Prof. Dr. Ramiz Asker ve çalışmaları hakkında bilgi verilmiş ve Prof. Dr. Ramiz Asker ile Prof. Dr. Metin Ekici'nin Günbed yazması neşirlerindeki farklı okuyuşlarından birkaçı zikredilmiştir.

\footnotetext{
${ }^{3}$ İlgili hayvan adı için ayrıca bk. Uzuntaş, 2020: 124-125 (Dip. 40).

${ }^{4}$ İlgili hayvan adı için ayrıca bk. Uzuntaş, 2020: 140 (Dip. 80).
} 
Çalışmanın ön kapağının görseli verildikten sonra (s. 85), muhtevası üzerinde durulmuştur.

7. Dede Korkut “Gayıbdan Dürlü Haber Söyler” Miydi? (s. 87-99)

Berlin'de bulunan Kitâb-ı Oguznâme-i Türkî ve Tatarca darb-ı meseldür başlıklı yazmanın Heinrich Friedrich von Diez tarafından yayımlanan Denkwürdigkeiten von Asien adlı eserde Atasözleri şeklinde 36-75 arasındaki geleceğe ait tahminlerin verildiği, ol günleri görmeden söyledim,

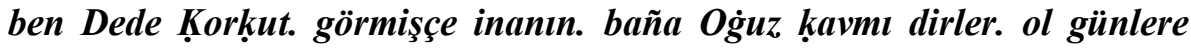
komagill! benim canım algill! käadir tanrım şeklinde biten 6 soylama ile bu soylamalara paralel ifadeler taşıyan Günbed yazmasının Ol günleri görmemişem. Men Dedem <Korḳud>, görmiş gibi söylerem cümleleri ile biten 18. soylamasinın (40/1-43/5) metinleri ve Sertkaya tarafindan yapılan aktarmaları (Sertkaya, 2020: 87-88) verilerek (s. 88-99) Dresden yazmasında Dede Korkut için söylenen (D3a/4-5) $)^{5}$ cümlelerine açıklık getirilmiştir.

8. Dede Korkut Kitabı'nın Kaç Yazma Nüshası Var? (s. 101-107)

Nüsha, varyant, versiyon, paralel metin kavramlarının tanımları yapıldıktan sonra Dede Korkut Kitabı'nın Dresden yazması ve Dresden yazmasının nüshaları hakkında bilgi verilmiş, Türk Tarih Kurumu Kütüphanesi (I/261)'deki 22 sahifelik Dede Korkut yazması ve Vatikan yazması Dresden yazmasının başka dip nüshalara dayanan varyantları, Türk Dil Kurumu Kütüphanesi A/87 numaradaki Arap harfli yazma versiyon metin, Dresden ve Vatikan yazmaları ile ilgisi olmadığı belirtilen Günbed yazması ise paralel metin olarak değerlendirilmiştir.

\section{Günbed Yazmasında Fauna (s. 109-159)}

Günbed yazmasındaki hayvanların incelendiği bu çalışmada, yazmada geçen 90'dan fazla hayvan aşağıdaki şekilde tasnif edilmiştir:

\section{"1. Memeli Hayvanlar (59)}

1.1. Ehlî Memeli Hayvanlar (38)

1.1.1. Avcr Olan Ehlî Memeli Hayvanlar (6): alavar tāzì, it og̉l1, kara it, kara köpek, tāzì, tula.

1.1.2. Av Olan Ehlî Memeli Hayvanlar (32): agayıl, ahtarma at, aḳca ḳoyın, at, ayġır ayḳır, bārgìr bārgìr at, bedev bedev at, bugur, buhtì deve, buzav, cüft gāv, çaluk at, dana, dümen ḳoyın, erkeç, keçi(si) ger, işşek, kartal ögec, kaybatan, kazaḳuc, keçi, ḳoç, ḳoçḳar, ḳoñur at, ḳoyın, kölük, körpe kuzı, kuba ner, oḳlak, saġın, tohulı, yügürük.

\footnotetext{
5 Dresden yazmasının sahife/satır numaraları Tezcan ve Boeschoten, 2018 neşrine göre verilmiştir.
} 
1.2. Vahşi Memeli Hayvanlar (21)

1.2.1. Avcı Olan Vahși Memeli Hayvanlar (13): ala ḳaplan, ala ḳaplan enigi, ala ḳaplan yavrısı, ala pars, așlan, aṣlan enigi, așlan yavrısı, böri börü, cānver, ḳaplan, kurt, kurd enigi kurt enigi, samūr.

1.2.2. Av Olan Vahşi Memeli Hayvanlar (8): ceyrān, davşan, fil, kıır teke, kıııl kèyik, maral, teke, 1 lhı.

2. Kanatl Hayvanlar (26)

2.1. Kuşlar $(1+23=24)$ : kuş.

2.1.1. Avcı Olan Kuşlar (13): alaca laçın, alıcı ḳuş, baḥrì ḳuş, boz ötelgi, çal ḳara ḳuş, doġan, ḳanatı ala saḳsaḳan, ḳara bürgüt, karçıḳay, laçın, şāhì şunḳar, şāhì şunḳar yavrısı, (yügürük) kı1k1.

2.1.2. Av Olan Kuşlar (10): çay ḳuşı, durna, fere bıldırçın, hoḳkār, kāaül-lice torḳay, ḳaz (ḳuşu), ḳuba ḳaz, ördek ḳuşu, șuna, yañıl ördek.

2.2. Zar Kanatlı Hayvanlar (2): ḳarınca, miçek.

3. Sürüngenler (4): ejdehā, ejder, evren, yılan.

4. Balıklar (1): sarı ala uşaḳ balug.

5. Dinî Motifli Hayvanlar (2): Burāḳ, Düldül” (Uzuntaş, 2020: 111-112).

Alfabetik olarak listelenen hayvan isimlerinin yazmadaki imlâs1 verildikten sonra transkripsiyonu yapılmış, cinsi, genel Latince adı (varsa özel Latince adı/bilimsel adı) verilmiş, son olarak da hayvan isminin kökeni tespit edilmeye çalışılmıştır. Hayvan isimlerinin tanımları yapıldıktan sonra mezkûr hayvanın betimlendiği kısımların birlikte verilmesine dikkat edilerek yazmada geçtiği ibâre veya cümleler sıralanmış, isimler sahife numarası/satır numarası şeklinde gösterilerek metindeki yerleri belirtilmiştir (Uzuntaş, 2020: 112).

Günbed yazmasındaki hayvanların incelendiği bu çalışmayla Türk dilinin hayvan isimleri konusundaki zenginlik ve çeşitliliği bir kez daha ortaya konulmuştur.

10. Dede Korkut Kitabı'nın Günbed Yazmasında Kaç Tane Boy (Veya Boylama) Var? (s. 161-165)

Günbed yazması nâşirlerinden Yusuf Azmun tarafindan "Salur Kazan'ın Aras Suyu ile Kars Kal'asını aldugı boy" şeklinde adlandırılan 48/7-51/14 sahifeleri arasındaki metnin neden boy(lama) olarak değerlendirilmesi gerektiği üzerinde durulmuş, bazı araştırmacılara göre boy(lama) sayılmayan bu metnin müstakil bir boy(lama) olduğu delilleri ile ortaya konulmuştur. Sertkaya da Azmun gibi metinde iki boy(lama) olduğu görüşündedir. 
Eserin Dizin bölümünde (s. 167-173), eserdeki şahıs isimleri, mevcut imlâlarına göre isim-soy isim şeklinde alfabetik olarak sıralanarak zikredildikleri sahife numaraları verilmiştir [Örneğin Yusuf 13, 13, 13, 14, 14, 14, 15, 15, 15, 26 bk. Yusuf Azmun (Sertkaya ve Uzuntaş, 2020: 173b)]. Aynı ismin farklı imlâlarına bk./krş. kısaltmaları ile göndermeler yapılarak [Örneğin Yusuf Bey 26 krş. Yusuf bk. Yusuf Azmun (Sertkaya ve Uzuntaş, 2020: 173b)] eserde değişik imlâlarla kullanılan isimlere toplu olarak erişebilme kolaylığı sağlanmıştır.

Dede Korkut Kitabı'nın Günbed yazması üzerine yazılan on farklı araştırma ve inceleme yazısının bir araya getirildiği bu eserde, yazmanın muhtevası ile ilgili yapılan değerlendirmeler ve yer yer mevcut diğer yazmalarla mukayesesi neticesinde elde edilen verilerden hareketle gerek Günbed yazmasının gerekse diğer yazmalardaki bazı tartışmalı ibârelerin anlaşılmasını kolaylaştıracak çeşitli bilgilere ulaşılabilmektedir. Bu eser ile Türkiye'deki Dede Korkut çalışmalarına bir yenisi daha eklenmiştir. Dede Korkut üzerinde çalışanlara faydalı olacağını umuyoruz.

\section{KAYNAKÇA}

AZMUN, Yusuf (2019), Dede Korkut'un Üçüncü Elyazması, Yeni Soylamalar ve Boylar (Hikâyeler) ile Türkmen Sahra Nüshası, Giriş - Metin - Çeviri Sözlük - Tipkıbasım, Kutlu Yayınevi, 1. baskı, İstanbul.

ERGIN, Muharrem (2011), Dede Korkut Kitabı I. Giriş-Metin-Tıpkıbasım, Türk Dil Kurumu Yayınları, 8. baskı, Ankara.

SERTKAYA, Osman Fikri ve UZUNTAȘ, Hülya (2020), Dede Korkut'un Günbed Yazması Üzerine Araştırmalar ve Incelemeler, Bilge Kültür-Sanat Yayınları, 1. baskı, İstanbul.

TEZCAN, Semih ve BOESCHOTEN, Hendrik (2018), Dede Korkut Oğuznameleri, Yapı Kredi Yayınları, 5. baskı, İstanbul. 